This item was submitted to Loughborough's Research Repository by the author.

Items in Figshare are protected by copyright, with all rights reserved, unless otherwise indicated.

\title{
Novel microstructured polyol-polystyrene composites for seasonal heat storage
}

PLEASE CITE THE PUBLISHED VERSION

https://doi.org/10.1016/j.apenergy.2016.03.023

PUBLISHER

(C) Elsevier

VERSION

AM (Accepted Manuscript)

\section{PUBLISHER STATEMENT}

This work is made available according to the conditions of the Creative Commons Attribution-NonCommercialNoDerivatives 4.0 International (CC BY-NC-ND 4.0) licence. Full details of this licence are available at: https://creativecommons.org/licenses/by-nc-nd/4.0/

\section{LICENCE}

CC BY-NC-ND 4.0

\section{REPOSITORY RECORD}

Puupponen, Salla, Valtteri Mikkola, Tapio Ala-Nissila, and Ari Seppala. 2019. "Novel Microstructured Polyolpolystyrene Composites for Seasonal Heat Storage". figshare. https://hdl.handle.net/2134/31890. 


\title{
Energy \& Environmental Science
}

\section{ARTICLE}

Cite this: DOI: 10.1039/xoxxooooox

\section{Novel microstructured polyol-polystyrene composites for seasonal heat storage}

\author{
Salla Puupponen, ${ }^{a \dagger}$ Valtteri Mikkola, ${ }^{a}$ Ari Seppälä ${ }^{a}$ and Tapio Ala-Nissila ${ }^{b, c}$
}

Received ooth January 2015,

Accepted ooth January 2015

DOI: $10.1039 /$ xoxxooooox

www.rsc.org/
We propose a robust route to prepare supercooling microstructured phase change materials (PCMs) suitable for long-term heat storage or thermal protection applications. The new preparation method is based on polymerization of high internal phase emulsion (HIPE). Two promising polyols, erythritol and xylitol, are successfully prepared as new type microencapsulated PCM-polystyrene composites with PCM mass fractions of $62 \mathrm{w}-\%$ and $67 \mathrm{w}-\%$, respectively, and average void diameter of $\sim 50 \mu \mathrm{m}$. Thermal properties of polyol-polystyrene composites and bulk polyols are studied thoroughly with differential scanning calorimetry (DSC). Microscale engineering has a significant impact on the thermal properties of polyols. Crystallization of the microscale erythritol is accelerated as compared to the crystallization of bulk PCM due to high fraction of solid surfaces in the polymer-polyol composites. Furthermore, crystallization properties of the microstructured erythritol are preserved similar in the cycling experiments. Crystallization of the bulk erythritol is found to strongly depend on the cooling rate, thermal history of the sample and surface roughness of the crucible, whereas these factors have only little impact on the crystallization of microstructured erythritol. In addition, microstructured polyolpolystyrene composites show anomalous enhancement in the specific heat as compared to bulk polyols. This enhancement may be originated from the strong polyol-surfactant interactions occurring in the composites.

\section{Introduction}

Growing energy consumption requires development of more efficient ways to produce and use energy than available to date. High efficiency energy storage technology would greatly improve the effectiveness of intermittent energy conversion technologies and facilitate inconstant energy use. During the last decades, researchers have started to realise the potential of phase change materials (PCMs) as thermal energy storage (TES) materials due to their greater heat storage density as compared to traditional 'sensible' heat storages. By far the most researched PCMs are chemically stable nonpolar paraffins and fatty acids with moderate heats of fusion. These standard PCMs release the heat stored when the temperature decreases below the thermodynamic equilibrium phase change temperature $\left(\mathrm{T}_{\mathrm{eq}}\right)$ during solidification. Thus, these PCMs operate as 'thermal buffers' in short-term heat storages. ${ }^{1-3}$

Supercooling of many promising PCMs, such as salt hydrates and sugar alcohols, is considered to be the main disadvantage hindering their use in TES. However, supercooling could actually be utilized in seasonal heat storages. In this case, the heat could be stored in the supercooled liquid for an unlimited time at temperatures substantially lower to $\mathrm{T}_{\mathrm{eq}}$ and released by crystallization when the supplement heat is required. However, the metastable nature of supercooling liquids introduces some problems to the utilization of the phenomenon; the crystallization is not well controlled in the supercooled state and may be initiated spontaneously without any external interference. In addition, the slow speed of the crystallization front at the recalescense for macroscale volumes can be a major obstacle for reaching thermally efficient storage process. The problems related to crystallization of supercooling PCMs may be solved by micro- or nanoscale engineering. Distribution of the material into large number of microscale units greatly enhances the efficiency of solidification. ${ }^{4}$ In addition uncontrollable, spontaneous crystallization of supercooled liquid is avoided as PCM is divided into separate microscale cells by introducing discontinuities into the crystallized material. $^{5,6}$

Only a few studies to date have addressed the micro- or nanostructuring of supercooling PCMs. Sagara et al. ${ }^{5}$ studied the thermal properties of D-mannitol impregnated into nanosized silica pores, and Salaün et al. ${ }^{6,7}$ researched microencapsulation of sodium phosphate dodecahydrate (DSP) and xylitol using interfacial polymerization of poly(urea-urethane) films as encapsulating agent. The chemical structures of PCM microparticles were extensively examined in the studies ${ }^{6,7}$, but the melting and crystallization properties of the PCMs were not studied. The main finding of the study of Sagara et al. ${ }^{5}$ was that nanoengineering facilitated thermal endurance, but simultaneously the melting heat of the PCM greatly decreased.

Here, we propose a novel and unique route to prepare microstructured polyols. Two promising supercooling polyols; 
xylitol and erythritol, are chosen as model PCMs in this study. The new preparation method utilizes the polymerization of high internal phase emulsions (HIPEs) used generally for preparation of polymeric foams. ${ }^{8-10}$ By this new procedure, a large fraction of polyol can be captured inside micro-pores of polymer matrix in a robust manner. In addition to TES, the proposed PCM-crosslinked polystyrene composites could be promising thermal protection candidates, as a heat storage material and polystyrene with a low thermal conductivity are combined in the structure. ${ }^{11,12}$ Polymerization of HIPEs has previously been utilized for developing toner particles for electrophotographic printing. ${ }^{13,14}$ However, this technology has not been applied earlier to development of heat storage materials. In addition, thermal properties of the bulk and microscale polyols are extensively characterized here using differential scanning calorimetry (DSC). We focus particularly on the crystallization of supercooling PCMs that, in general, is only briefly reported in the literature.

\section{Experimental section}

\section{Materials and preparation methods}

Styrene (assay $\geq$ 99\%) and divinylbenzene (60-65 area\%, ethylvinylbenzene 34-39 area\% by GC) were supplied by Merck. Sorbitan monooleate (Span80, synthesis quality) from Merck was chosen for surfactant due to its optimal hydrophilic-lipophilic balance (HLB) of 4.3 for emulsification of water-in-oil system. ${ }^{9,10}$ Two radical initiators, polar potassium persulfate (KPS) from VWR and nonpolar azobisisobutyronitrile (AIBN) from Sigma-Aldirch were used to initiate the polymerizations.

\section{Preparation of polystyrene HIPE foams}

Polystyrene foams were prepared by polymerization of high internal phase emulsions. Conventional polymerized high internal phase emulsions (HIPEs) are microcellular foams produced typically by emulsification of water - hydrophobic monomer - hydrophobic surfactant tricomponent system, after which the continuous monomer phase is polymerized in the presence of a crosslinker agent. In our study, the preparation parameters were optimized in order to obtain closed-cell foam for development of microstructured PCMs.

Organic phase was prepared by mixing appropriate amounts of sorbitan monooleate (SMO) and styrene (St) for $\sim 5$ min using a magnetic stirrer. In some samples, the crosslinker agent divinylbenzene (DVB) was added to the organic phase. If nonpolar AIBN was used as an initiator, it was also added to the organic phase. The monomers were used without removing the inhibitors. Aqueous phase was prepared by mixing an appropriate amount of de-ionized water and KPS, if used as an initiator, with magnetic stirrer for $\sim 5 \mathrm{~min}$. The total mass of the wet samples was 50 grams, and mass fraction of the initiator was $0.15 \mathrm{wt}-\%$ in the samples. All reagents were weighed using the Precisa 360EP Executive PRO analysis scale with repeatability of $0.02 \mathrm{mg}$.

Emulsions were formed by a slow addition of the aqueous phase to the organic phase using a separating funnel and magnetic stirring.
Addition rate of the aqueous phase was kept as low as possible; generally the addition was complete in 20-30 min depending on the amount of water in the sample. Vaporization of volatile monomers was avoided by covering the samples carefully. Mixing was continued for 5-10 min after addition of the aqueous solution until a homogeneous, generally thick emulsion was obtained. The samples were taken either without, after $30 \mathrm{~s}$, or after $1.5 \mathrm{~min}$ of ultrasonic mixing. During the ultrasonic processing $(400 \mathrm{~W}$ power with Hielscher UP400S) the emulsions were placed in $\sim 10{ }^{\circ} \mathrm{C}$ water bath. The emulsions were polymerized in sealed glass bottles for $24 \mathrm{~h}$ at $60-70{ }^{\circ} \mathrm{C}$ in a ventilated oven. After polymerization, the caps were removed and water was vaporized from the foams by keeping the samples in the oven at $70-80{ }^{\circ} \mathrm{C}$ until the sample weight stabilized.

\section{Preparation of polyol-polystyrene composites}

Two polyols were studied as promising supercooling PCMs; powdered erythritol (food grade, Jungbunzlauer) and crystalline xylitol (food grade, Danisco.) Polyol-polystyrene composites were prepared by dissolving sugar alcohol at $\sim 50{ }^{\circ} \mathrm{C}$ to water during $\sim 10$ min using magnetic stirring, after which the samples were prepared similarly as described earlier, with the exception that the erythritol sample was mixed at $\sim 40{ }^{\circ} \mathrm{C}$ in order to prevent crystallization of the highly supersaturated erythritol-water solution during emulsification. Maximum amounts of polyols that could be dissolved in the aqueous phase without crystallization during emulsification were 70 and 60 wt- $\%$ of the aqueous phase mass for xylitol and erythritol, respectively. The sample compositions are presented in Table 1.

\section{Analysis methods}

Foam structures were determined with optical microscopy (Leica Polarized Optical Microscope) in transmitting mode. The structures of polyol-polystyrene composites were imaged using incident light due to opacity of the composites. Thin pieces of samples were cut with a sharp blade for microscopy imaging. Thermal properties of polyol-polystyrene composites and bulk PCMs were measured with Netzcsh DSC204FI Phoenix differential scanning calorimeter. Onset temperatures and latent heats were determined with accuracies of $\pm 0.5 \mathrm{~K}$ and $<1 \%$, respectively. The samples (10-20 mg) were hermetically sealed into aluminium crucibles. Three to six parallel measurements were conducted from each sample in order to obtain representative results. Two crucibles with different surface roughnesses, presented in Fig. 1., and a temperature range from -30 to $140{ }^{\circ} \mathrm{C}$ were used. In addition, preliminary crystallization tests of xylitol were conducted by cooling the samples to at most $-50{ }^{\circ} \mathrm{C}$ and held there overnight. Two scanning rates of 0.5 and $5 \mathrm{~K} / \mathrm{min}$ were used for studying the melting/crystallization kinetics and five to ten sequential phase change cycles were used for investigating the repeatability of melting/solidification. Specific heats of the samples were determined using a $5 \mathrm{~K} / \mathrm{min}$ scanning rate. Stability of the supercooled state was assessed for few bulk and microstructured erythritol samples using a five hour long holding period at $50{ }^{\circ} \mathrm{C}, 5$ $\mathrm{K} / \mathrm{min}$ scanning rate and a crucible with a smooth surface. No crystallization was observed during these holding periods. 


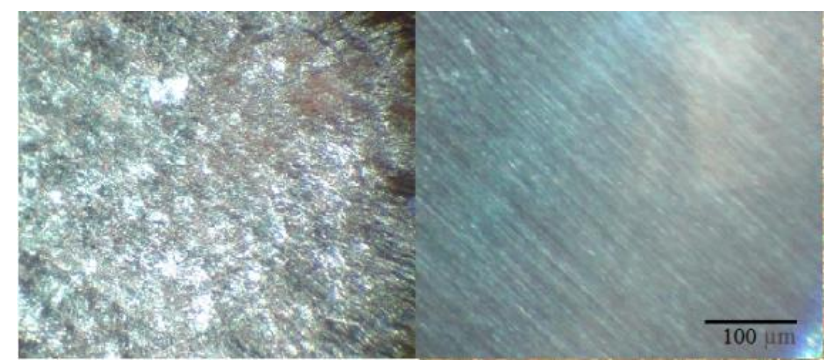

Fig. 1. Optical microscopy images of crucibles used in the DSC experiments. Left: crucible with a rough surface, right: crucible with a smooth surface. The scale bar $(100 \mu \mathrm{m})$ is the same the in both images.

Table 1. Sample compositions. Abbreviations: AIBN - azobisisobutyronitrile, DVB - divinylbenzene, HIPE-ery - erythritol filled HIPE, HIPE-xyl - xylitol filled HIPE, KPS- potassium persulfate, SMO - sorbitan monooleate

\begin{tabular}{|c|c|c|c|c|c|}
\hline Sample name & $\begin{array}{l}\text { polyol/aqueous phase } \\
\text { (wt-\%) }\end{array}$ & $\begin{array}{c}\text { aqueous phase } \\
\text { (wt-\%) }\end{array}$ & $\begin{array}{l}\text { SMO/organic } \\
\text { phase (wt- } \% \text { ) }\end{array}$ & $\begin{array}{l}\text { DVB/organic phase } \\
\text { (wt- } \%)\end{array}$ & Initiator \\
\hline HIPE-1 & - & 60 & 7 & 0 & AIBN \\
\hline HIPE-2 & - & 70 & 7 & 0 & AIBN \\
\hline HIPE-3 & - & 80 & 7 & 0 & AIBN \\
\hline HIPE-4 & - & 90 & 7 & 0 & AIBN \\
\hline HIPE-5 & - & 70 & 3 & 0 & KPS \\
\hline HIPE-6 & - & 70 & 5 & 0 & KPS \\
\hline HIPE-7 & - & 70 & 7 & 0 & KPS \\
\hline HIPE-8 & - & 70 & 9 & 0 & KPS \\
\hline HIPE-9 & - & 70 & 15 & 0 & KPS \\
\hline HIPE-10 & - & 70 & 5 & 5 & KPS \\
\hline HIPE-11 & - & 70 & 5 & 10 & KPS \\
\hline HIPE-12 & - & 70 & 5 & 20 & KPS \\
\hline HIPE-13 & - & 70 & 5 & 30 & KPS \\
\hline HIPE-14 & - & 70 & 5 & 40 & KPS \\
\hline HIPE-ery & 60 & 74.3 & 5 & 30 & KPS \\
\hline HIPE-xyl & 70 & 73.4 & 5 & 30 & KPS \\
\hline
\end{tabular}

\section{Results and discussion}

\section{Optimization of the polystyrene foam structure}

Influence of the amount of the aqueous phase, initiator type, surfactant concentration and length and intensity of mixing on the foam structure were studied.

The impact of the amount of the aqueous phase on the foam structure was tested by varying the aqueous phase in the emulsion from 60 to 90 wt- $\%$. Samples containing 70 or 80 wt- $\%$ aqueous phase produced the most stable emulsions that did not collapse during the water vaporization. A smaller amount of water (60 wt- $\%)$ produced inhomogeneous foam with hard bulk-polystyrene phase on top, whereas a sample with $90 \mathrm{wt}-\%$ of water did not produce an emulsion at all. Therefore, 70 and 80 wt- $\%$ emulsions were chosen for further studying.

Two radical initiators, nonpolar AIBN and polar KPS, were tested for polymerization initiation. No significant differences between the initiators were observed, but KPS initiated samples seemed to be more homogeneous and thus, KPS was chosen for further sample preparation. Ionic KPS initiates the polymerization from the styrenewater interface, whereas nonpolar AIBN initiates the polymerization randomly from the bulk styrene. Quick solidification of the oil-water interfaces may enhance the emulsion stability by preventing rapidly the coalescence of dispersed aqueous droplets.
Surfactant concentration impacts greatly on the foam structure as presented in Fig. 2. Foams with closed-cell pores were obtained with SMO/organic phase ratio of $5 \mathrm{wt}-\%$. Emulsion did not form altogether with lower SMO/organic phase ratio of $3 \mathrm{wt}-\%$, whereas slightly higher surfactant concentration of $7 \mathrm{wt}-\%$ resulted in formation of small windows between the micropores.

The micropores were strongly interconnected when SMO/organic phase ratio was increased further to 9 and $15 \mathrm{wt}-\%$. Williams and Wrobleski ${ }^{9}$ proposed that small amount of surfactant results in completely closed water droplets due to formation of a thin, monomolecular surfactant layer on the droplet surfaces. As the amount of surfactant increases the polymer wall between water droplets becomes thinner as the hydrophobic surfactant molecules penetrate deeper into the organic phase creating small passages between the water droplets. Since closed-cell structure was desired for creation of microstructured PCMs, SMO/organic phase ratio of 5 wt- $\%$ was selected for further preparation. Two aqueous phase fractions, 70 and 80 wt- $\%$ were tested using this surfactant concentration. Closed-cell structure with 80 wt- $\%$ of water was extremely difficult to produce, and thus other samples were prepared with 70 wt- $\%$ aqueous phase amount. 


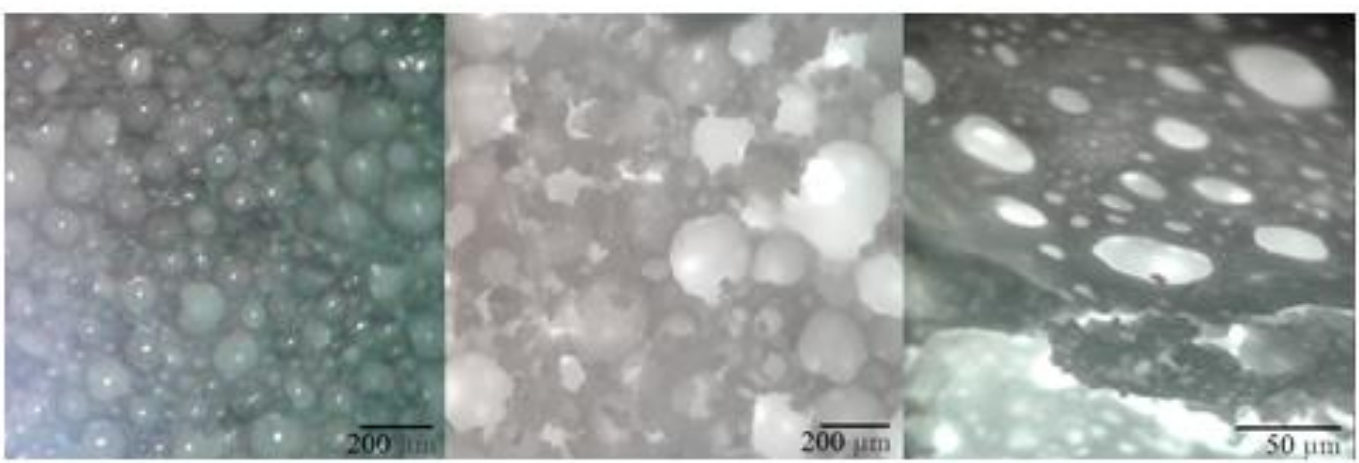

Fig. 2. Optical microscopy images of foam samples with different SMO/organic phase ratios.

Left: HIPE-6 (5 wt-\% SMO/organic phase), middle: HIPE-7 (7 wt-\% SMO/St), right: HIPE-9 (15 wt-\% SMO/St.)

Divinylbenzene stabilizes the foam system by crosslinking the polystyrene chains quickly together during polymerization. ${ }^{9,10}$ The influence of DVB concentration on the cell structure was tested by varying the DVB weight fraction between 5 and $40 \mathrm{wt}-\%$ in the organic phase. All foam samples contanining DVB were relatively stable and demonstrated no or little collapse during vaporization of water. It was found out that increasing DVB resulted in slight decrease in void size and - distribution. Simultaneously, the emulsion softness increased.

The void sizes and void size distributions were found to decrease as the DVB concentration increased from 10 to $30 \mathrm{wt}-\%$ in the organic phase. HIPE-10 sample with $5 \mathrm{wt}-\%$ of DVB had relatively narrow void size distribution with an average void size of $\sim 200 \mu \mathrm{m}$, but was extremely brittle. HIPE-11 and HIPE-12 samples containing 10 and $20 \mathrm{wt}-\%$ DVB in the organic phase had a wide distribution of void sizes; most of them were relatively small (10-40 $\mu \mathrm{m})$ but also several larger voids $(80-120 \mu \mathrm{m})$ could be observed. HIPE-13 containing $30 \mathrm{wt}-\%$ DVB in the organic phase had a narrower size distribution with an average pore size of $\sim 40 \mu \mathrm{m}$. In addition, the mechanical properties of HIPE-13 were good; the foam was hard but not brittle. When DVB concentration was further increased to $40 \mathrm{wt}-$ $\%$ in the organic phase, the emulsion softness significantyl increased destroying the emulsion stability. Therefore, DVB fraction of $30 \mathrm{wt}-$ $\%$ of the organic phase was chosen for further preparation. The average void sizes of the samples were determined by calculating the mean average of $\sim 50$ voids.

The effect of mixing was tested by mixing the emulsions in three different ways. The emulsions were first formed as in the conventional HIPE method using only magnetic stirring and slow addition rate of the aqueous phase. ${ }^{8-10}$ Part of the emulsion was further emulsified ultrasonically and the samples were taken after $\sim 30 \mathrm{~s}$ and $\sim 1.5 \mathrm{~min}$ mixing times. Generally, a short ultrasonic processing of $\sim 30 \mathrm{~s}$ increased the emulsion viscosity and thus the emulsion stability, whereas longer mixing of $\sim 1.5 \mathrm{~min}$ destroyed the emulsion structure. The degradation was noticed by an abrupt decrease in the emulsion viscosity after $\sim 1$ min ultrasonic processing.
These impacts can be understood by the ultrasound's ability to both initiate polymerization and cause depolymerization.

Ultrasonic processing may initiate the polymerization of vinylic groups alone ${ }^{15-17}$ or accelerate the homolytic fission of chemical initiators due to extremely high local temperatures in the vicinity of collapsing bubbles. ${ }^{18-20}$ In addition, ultrasonic cavitation causes degassing resulting in depletion of oxygen that enhances the polymerization by preventing chain transfer reactions. Ultrasonic treatment may also cause polymer degradation due to possible cleavage of polymeric chains in violent mixing conditions. ${ }^{19,21,22}$ The origin of this effect is still under some debate, but cavitation occurring during high intensity mixing has shown to have a significant impact on degradation. This effect has been observed to be relatively independent on the chemistry of the polymer, but rather depend on the polymer chain length. Degradation has been reported to propagate faster for low molecule weight polymers at low temperatures and dilute solutions, as in the case of emulsions studied. ${ }^{19}$

\section{Polyol-polystyrene composite structures}

Solubility of polyols and densities of polyol - water solutions are important factors in successful preparation of polyol - polystyrene composites. The higher the solubility the more PCM can in principle be engaged into the HIPE structure. Xylitol is highly soluble in water $\left(\sim 62 \mathrm{~g} / 100 \mathrm{~g} \mathrm{H}_{2} \mathrm{O}\right.$ at $\left.20{ }^{\circ} \mathrm{C}\right)$, whereas the solubility of erythritol is poorer $\left(\sim 32 \mathrm{~g} / 100 \mathrm{~g} \mathrm{H}_{2} \mathrm{O}\right.$ at $20{ }^{\circ} \mathrm{C}$.) However, the solubility of erythritol increases substantially at higher temperatures, being $\sim 78 \mathrm{~g} / 100 \mathrm{~g} \mathrm{H}_{2} \mathrm{O}$ at $80{ }^{\circ} \mathrm{C}$. The solubility of xylitol is $\sim 93 \mathrm{~g} / 100 \mathrm{~g} \mathrm{H}_{2} \mathrm{O}$ at $80{ }^{\circ} \mathrm{C}$.

The maximum polyol fractions in the aqueous phase that maintained stable liquids during emulsification without crystallization were 60 and $70 \mathrm{wt}-\%$ for erythritol and xylitol, respectively. In the preparation of erythritol filled HIPE, temperature was kept at $\sim 40$ ${ }^{\circ} \mathrm{C}$ during emulsification in order to prevent crystallization of the highly supersaturated polyol solution. 
A)

B)
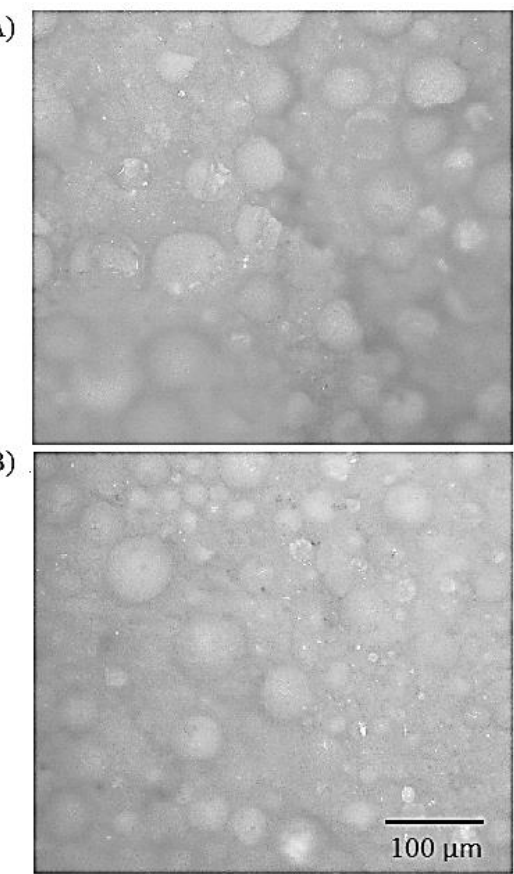

Fig. 3. Optical microscopy images of polyol-polystyrene composites: A) xylitol filled HIPE (HIPE-xyl) and B) erythritol filled HIPE (HIPE-ery). The scale bar $(100 \mu \mathrm{m})$ is same in both images.

It has to be acknowledged that when the system is emulsified at elevated temperatures, polymerization may start already in the mixing stage. However, no significant changes in the appearance of the erythritol sample were observed as compared to other samples produced at $10{ }^{\circ} \mathrm{C}$. Densities of the solutions significantly influence the stability of emulsions; dissolution of polyols notably increases the density of the aqueous phase causing destruction of the emulsion structure due to density differences between the organic and aqueous phases. The organic phase density used for preparation of polyol - polystyrene composites (30 wt- $\%$ DVB, $5 \mathrm{wt}-\%$ SMO and $65 \mathrm{wt}-\% \mathrm{St}$ ) was $\sim 0.91 \mathrm{~g} / \mathrm{ml}$, whereas the densities of $60 \mathrm{wt}-\%$ erythritol- and 70 wt- $\%$ xylitol-water solutions were $\sim 1.24 \mathrm{~g} / \mathrm{ml}$ and $\sim 1.25 \mathrm{~g} / \mathrm{ml}$, respectively. Therefore, the densities of polyol-water solutions were $\sim 35 \%$ higher than that of the organic phase.

The best polyol filled foams were obtained when the emulsions were mixed $30 \mathrm{~s}-1.5 \mathrm{~min}$ ultrasonically. The instability of emulsions formed by magnetic stirring only may be understood by a rapid phase separation due to the great density differences. Ultrasonic processing initiates polymerization when the continuous phase begins to solidify preventing the sedimentation of dense aqueous phase.

Optical microscopy images of the polyol-polystyrene samples are presented in Fig. 3. The average void sizes of xylitol and erythritol filled HIPEs were $\sim 60 \mu \mathrm{m}$ and $\sim 40 \mu \mathrm{m}$, respectively. The void sizes of both samples varied between 15-90 $\mu \mathrm{m}$ indicating relatively wide pore size distribution typical for emulsions mixed mechanically. ${ }^{30}$

\section{Thermal properties of erythritol and erythritol-polystyrene composite}

Erythritol crystallizes spontaneously when sufficiently cooled ${ }^{23-25}$, whereas many other polyols, such as xylitol, are remarkably stable in the supercooled state and thus are difficult to crystallize spontaneously only by cooling the sample. ${ }^{26,27}$ Lower supercooling degree of erythritol can be understood by similarities of the most stable crystalline and melt erythritol conformers; both possess straight backbone conformations. ${ }^{23}$ Main thermal properties of bulk erythritol are presented in Table 2.

Table 2. Thermal properties of bulk erythritol. Abbreviations: $T_{p c}$ melting - / crystallization temperature, $\Delta H$ - latent heat of melting/crystallization. Repeatability of $\mathrm{T}_{\mathrm{pc}}$ and $\Delta \mathrm{H}$ are reported after the average values.

\begin{tabular}{ccc}
\hline Measurement & $T_{p c}\left({ }^{\circ} \mathrm{C}\right)$ & $\Delta H(\mathrm{~J} / \mathrm{g})$ \\
\hline Melting $($ smooth crucible) & & \\
$0.5 \mathrm{~K} / \mathrm{min}$ & $119 \pm 1$ & $329 \pm 14$ \\
$5 \mathrm{~K} / \mathrm{min}$ & $116 \pm 1$ & $319 \pm 20$ \\
Crystallization (smooth crucible) & & \\
$0.5 \mathrm{~K} / \mathrm{min}$ & $25 \pm 28$ & $-204 \pm 26$ \\
$5 \mathrm{~K} / \mathrm{min}$ & $22 \pm 31$ & $-101 \pm 65$ \\
$0.5 \mathrm{~K} / \mathrm{min}$ & & \\
$5 \mathrm{~K} / \mathrm{min}$ & $52 \pm 30$ & $-204 \pm 25$ \\
Crystallization (rough crucible) & $24 \pm 20$ & $-203 \pm 20$ \\
\hline
\end{tabular}

The average melting temperature and melting heat of bulk erythritol were $\sim 118{ }^{\circ} \mathrm{C}$ and $\sim 324 \mathrm{~J} / \mathrm{g}$, respectively, being consistent with the values reported for pure erythritol in the literature $\left(117-118{ }^{\circ} \mathrm{C}\right.$ and $319-323 \mathrm{~J} / \mathrm{g}$ ). ${ }^{25,28,29}$ The melting temperature and melting heat remained constant between parallel measurements and sequential melting-crystallization cycles, albeit the melting heat was slightly higher when the lower heating rate of $0.5 \mathrm{~K} / \mathrm{min}$ was used. The endpoint of the melting was $\sim 135^{\circ} \mathrm{C}$ despite the used heating rate. The effect of surface roughness and cooling rate on the crystallization of bulk erythritol is shown in Fig. 4. Bulk erythritol crystallized rather coincidentally; the crystallization temperatures varied greatly between the parallel measurements and sequential melting-crystallization cycles. Crystallization may be induced by impurities as well as surface roughness of the crucible. Once the crystallization is induced, it progresses as a crystallization front through the whole bulk PCM.

The cooling rate of $5 \mathrm{~K} / \mathrm{min}$ was observed to be inadequate due to the slow speed of crystallization front when a crucible with a smooth surface was used. 
A)

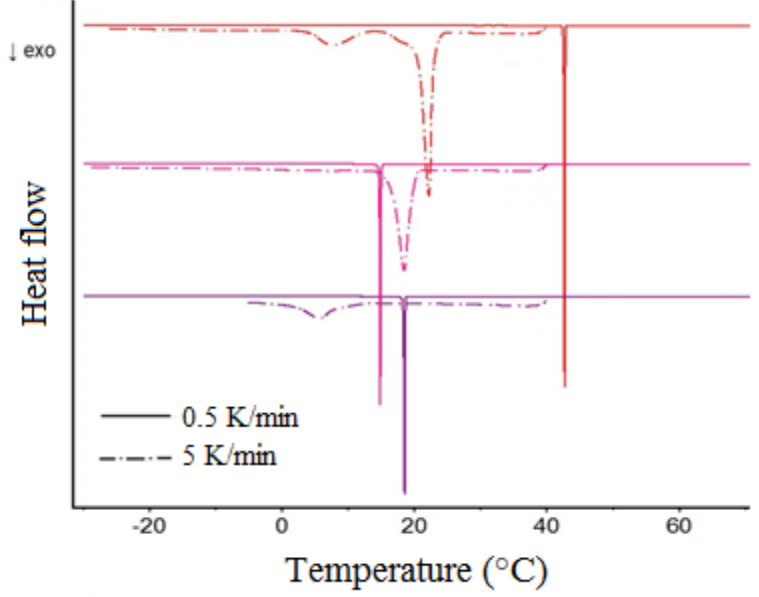

B)

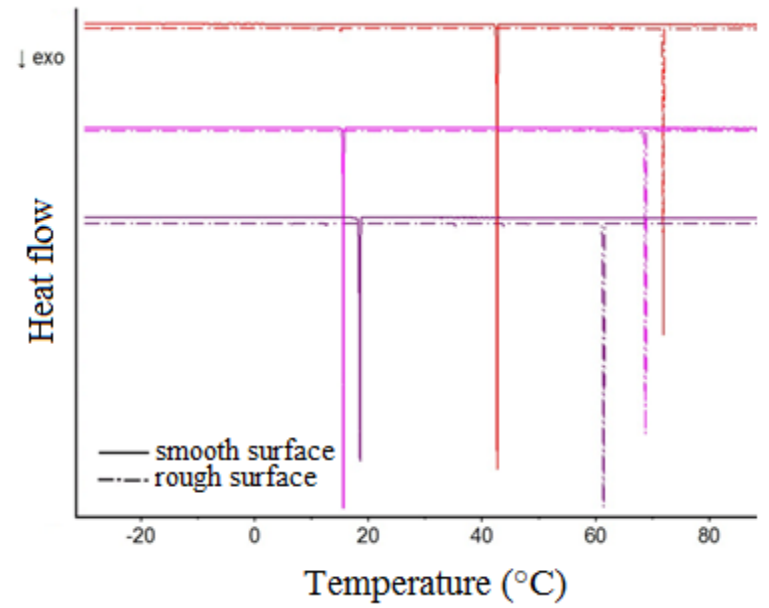

Fig. 4. Typical cooling DSC curves for bulk erythritol: A) Effect of the cooling rate and B) surface roughness on the crystallization. Superposed curves present sequential crystallization cycles

The smooth surface provides fewer nucleation sites, and therefore crystallization begins only from a few spots. In this case, the time scale in $5 \mathrm{~K} / \mathrm{min}$ measurements is too short to allow complete crystallization. Upon complete crystallization, the absolute value of crystallization heat was $\sim 200 \mathrm{~J} / \mathrm{g}$.

Furthermore, in some $5 \mathrm{~K} / \mathrm{min}$ measurements, bulk erythritol did not crystallize until it was heated up again from $-30{ }^{\circ} \mathrm{C}$ to $-10{ }^{\circ} \mathrm{C}$. This behavior was found to occur more often after several melting-crystallization cycles. In addition, occasionally a small exothermic peak was observed between -5 and $50{ }^{\circ} \mathrm{C}$ during heating indicating crystallization of conformer with smaller frequency of occurrence. Similar behavior has been reported earlier for pure erythritol. ${ }^{24}$

Surface roughness had a great influence on the crystallization of bulk erythritol when a low cooling rate of $0.5 \mathrm{~K} / \mathrm{min}$ was used. Indeed, the onset of crystallization increased on average from $\sim 25{ }^{\circ} \mathrm{C}$ to $\sim 52$ ${ }^{\circ} \mathrm{C}$ when a rough surface crucible was used. The rough surface introduces nucleation sites particularly if the wetting between supercooled PCM and the crucible is sufficient resulting in decrease in supercooling. However, microstructure of the crystallization surface greatly affects the nucleation process; in some measurements the bulk erythritol crystallized at $60-70{ }^{\circ} \mathrm{C}$ in the sequential cycles, whereas in other cases the crystallization temperature varied between $15-40{ }^{\circ} \mathrm{C}$. This effect was not observable when a higher cooling rate of $5 \mathrm{~K} / \mathrm{min}$ was used.

Main thermal properties of the erythritol-polystyrene composite are presented in Table 3.
Table 3. Thermal properties of the erythritol-polystyrene composite. Abbreviations: $T_{p c}-$ melting/crystallization temperature, $\Delta H$-latent heat of melting/crystallization. Repeatability of $\mathrm{T}_{\mathrm{pc}}$ and $\Delta \mathrm{H}$ are reported after the average values. $\Delta H_{\text {meas. }} / \Delta H_{\text {calc. }}-$ measured/calculated $\Delta H$ (cf. Eq. (1)) Latent heats are reported per total mass of the composite.

\begin{tabular}{cccc}
\hline Measurement & $T_{p c}\left({ }^{\circ} \mathrm{C}\right)$ & $\Delta H(\mathrm{~J} / \mathrm{g})$ & $\Delta H_{\text {meas } .} / \Delta H_{\text {calc. }}$ \\
\hline $\begin{array}{c}\text { Melting } \\
\text { (smooth crucible) }\end{array}$ & & & \\
$0.5 \mathrm{~K} / \mathrm{min}$ & $110 \pm 6$ & $143 \pm 4$ & 0.71 \\
$5 \mathrm{~K} / \mathrm{min}$ & $110 \pm 10$ & $151 \pm 20$ & 0.77 \\
$\begin{array}{c}\text { Crystallization } \\
\text { (smooth crucible) }\end{array}$ & & & \\
$0.5 \mathrm{~K} / \mathrm{min}$ & $45 \pm 4$ & $-100 \pm 5$ & 0.80 \\
$5 \mathrm{~K} / \mathrm{min}$ & $32 \pm 5$ & $-86 \pm 15$ & 1.38 \\
$\begin{array}{c}\text { Crystallization } \\
\text { (rough crucible) }\end{array}$ & & & \\
$0.5 \mathrm{~K} / \mathrm{min}$ & $45 \pm 2$ & $-109 \pm 10$ & 0.87 \\
$5 \mathrm{~K} / \mathrm{min}$ & $40 \pm 5$ & $-92 \pm 5$ & 0.74 \\
\hline
\end{tabular}

The average melting temperature of microstructured erythritol was $\sim 7.5^{\circ} \mathrm{C}$ lower than that of bulk erythritol. In addition, HIPE-ery melted at a wider temperature range than bulk erythritol indicating a broad void size distribution due to mechanical mixing in the emulsification. $^{30,31}$ 
If surface effects are ignored, the latent heat of polyol-polystyrene composite can be calculated from the mass fraction of the PCM in the product as:

$\Delta H_{\text {calc. }}=\varphi \Delta H_{\text {bulk }}$

where $\varphi$ is the mass fraction of the polyol in the product and $\Delta H_{b u l k}$ is the melting/crystallization heat of bulk polyol.

The measured melting heat of HIPE-ery was on average $74 \%$ of the theoretical one obtained from Equation (1). The lower melting heat and - temperature of nanomaterials is usually explained by the large fraction of a nonfreezing liquid layer in small-scale systems resulting in lower free energy. ${ }^{5,30}$ However, this effect should not be dominant in the microscale samples studied here, in which the surface area-tovolume ratio is substantially lower as compared to nanoscale systems.

The foam structure is likely to have a significant impact on the thermal properties of PCM in the composite. The void surfaces are surrounded by the surfactant molecules whose polar head groups penetrate inside the voids. The headgroup of SMO contains several hydroxyl groups resulting in strong interactions between the headgroups and the polyol molecules on the void surfaces. The filling fraction (estimated from the erythritol densities and the sample volume) of the composite is relatively low (54\% and $47 \%$ for the melt and solid HIPE-ery, respectively) and thus, most of the voids are not completely filled with the polyol allowing large fraction of the PCM to occupy the surface positions where the strongest surfactant/ polyol interactions occur. In addition, some erythritol molecules may migrate further into the foam structure during water vaporization enhancing the surfactant/polyol or polystyrene/polyol interactions. These interactions and possible distortions caused by them may largely determine the crystal structure of the microstructured erythritol, since the heterogeneous nucleation is likely to occur on the surfaces.

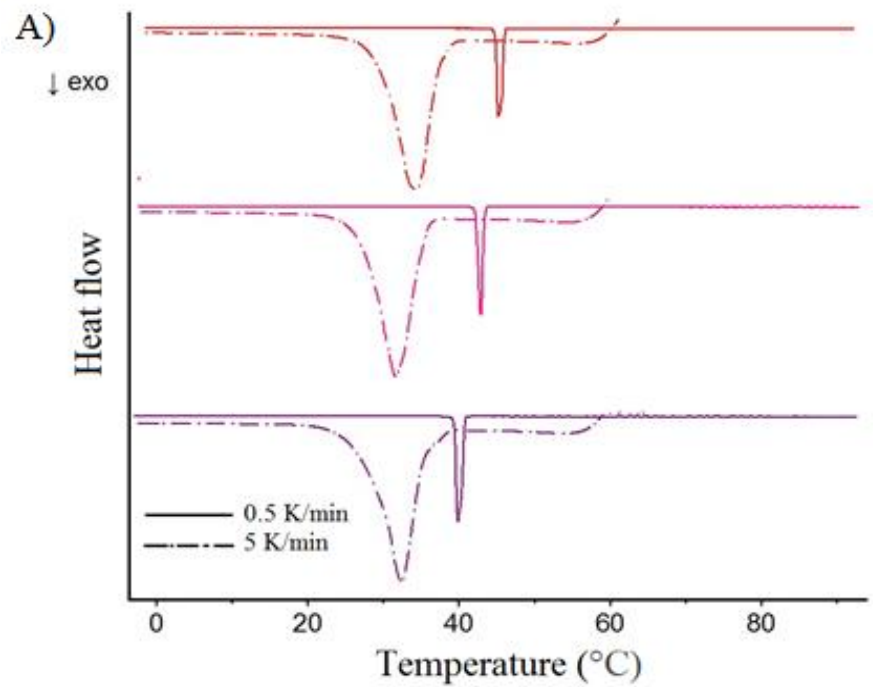

Influence of the cooling rate and surface roughness on the crystallization of microscale erythritol is presented in Fig. 5.

Crystallization of the erythritol-polystyrene composite seems substantially more reproducible than that of bulk erythritol. Indeed, the crystallization temperatures, heats and peak shapes of erythritolpolystyrene composite varied substantially less than those of the bulk erythritol.

The crystallization temperatures of HIPE-ery were between 41-49 ${ }^{\circ} \mathrm{C}$ and $27-45{ }^{\circ} \mathrm{C}$ when 0.5 and $5 \mathrm{~K} / \mathrm{min}$ cooling rates were used, respectively. Therefore, the higher cooling rate slightly increased the supercooling degree of HIPE-ery. The crystallization heats were between $70-105 \mathrm{~J} / \mathrm{g}$ with both cooling rates, lying in a narrower range than in the case of bulk PCM. The measured crystallization heat is $\sim 20 \%$ lower $(0.5 \mathrm{~K} / \mathrm{min})$ than the calculated value obtained from Equation (1).

The crystallization heats of both bulk and microstructured erythritol samples were substantially lower than the corresponding melting heats. The crystallization heat reduction can be explained by the large supercooling degree of erythritol and differences in the specific heats of solid and liquid PCM:

$\Delta H_{\text {Tm. }}-\Delta H_{\text {Tcryst. }}=\int_{T_{\text {cryst. }}}^{T_{m .}}\left(c_{p, \text { liquid }}-c_{p, \text { solid }}\right) d T$

where $T_{m}$. is the melting temperature, $T_{\text {cryst }}$. is the crystallization temperature, $\Delta H_{T m}$. and $\Delta H_{\text {Tcryst. }}$ are the latent heats in $T_{m}$. and $T_{\text {cryst. }}$, respectively, and $c_{p \text {,liquid }}$ and $c_{p, \text { solid }}$ are the specific heats of liquid and solid PCM, respectively.

Values used for determination of crystallization heat reduction in the erythritol samples are presented in Table 4. The specific heats of erythritol samples and comparison of measured and calculated crystallization heat of bulk erythritol as a function of temperature are showed in Fig. 6.

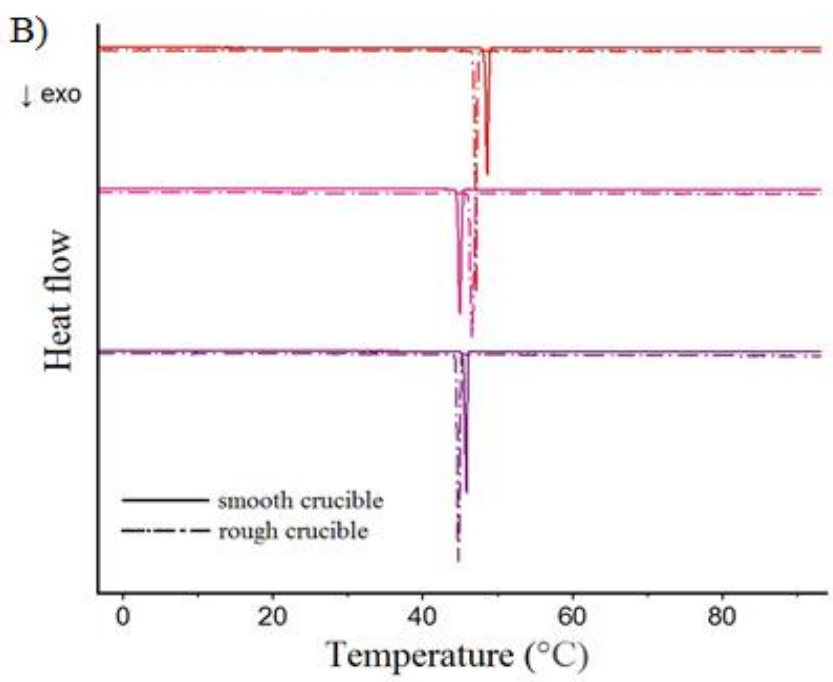

Fig. 5. Typical cooling DSC curves for erythritol-polystyrene composite: A) Effect of cooling rate and B) surface roughness on crystallization. Superposed curves present sequential crystallization cycles 
Table 4. Crystallization heat reduction of the erythritol samples. Abbreviations: $c_{p, s o l i d}-$ specific heat of solid PCM, $c_{p, l i q u i d}-$ specific heat of liquid PCM, $T_{m}$ - melting temperature, $T_{\text {cryst. }}$ - crystallization temperature, $\Delta H_{T m} . \Delta H_{T c r y s t .}$ - difference in latent heats at $T_{m .}$ and $T_{c r y s t}$, $\Delta H_{\text {meas.,cryst. }}$ - measured crystallization heat, $\Delta H_{\text {calc.,cryst. }}-$ calculated crystallization heat (cf. Eq (2).) Specific heats are tabulated at $40{ }^{\circ} \mathrm{C}, T_{m}$, $T_{\text {cryst. }}$ and $\Delta H_{\text {meas., cryst. }}$ are the average measured values $(0.5 \mathrm{~K} / \mathrm{min}$, smooth surface crucible)

\begin{tabular}{cccccccc}
\hline Sample & $\begin{array}{c}c_{p, \text { solid }} \\
(\mathrm{J} / \mathrm{gK})\end{array}$ & $\begin{array}{c}c_{p, \text { liquid }} \\
(\mathrm{J} / \mathrm{gK})\end{array}$ & $\begin{array}{c}T_{m .} \\
\left({ }^{\circ} \mathrm{C}\right)\end{array}$ & $\begin{array}{c}T_{\text {cryst. }} \\
\left({ }^{\circ} \mathrm{C}\right)\end{array}$ & $\begin{array}{c}\Delta H_{T m .}-\Delta H_{\text {Tcryst. }} \\
(\mathrm{J} / \mathrm{g})\end{array}$ & $\begin{array}{c}\Delta H_{\text {calc., cryst. }} \\
(\mathrm{J} / \mathrm{g})\end{array}$ & $\begin{array}{c}\Delta H_{\text {meas., cryst. }} \\
(\mathrm{J} / \mathrm{g})\end{array}$ \\
\hline bulk erythritol & 1.42 & 2.51 & 119 & 25 & -100.7 & -219.2 & $-204 \pm 26$ \\
HIPE-ery & 2.02 & 2.72 & 110 & 45 & -68.6 & -82.4 & $-100 \pm 5$ \\
\hline
\end{tabular}

Specific heats of solid and liquid erythritol samples differ greatly from each other, giving rise to the crystallization heat reduction observed in the measurements. Peculiarly, the specific heat of HIPEery was larger than that of bulk erythritol despite the lower specific heat of polystyrene foam $\left(\mathrm{c}_{\mathrm{p}, \mathrm{HIPE}-13 \text { foam }}=1.31 \mathrm{~J} / \mathrm{gK}\right.$ at $40{ }^{\circ} \mathrm{C}$. $)$ The specific heat of HIPE-ery is larger both in solid and liquid state of PCM, but is more significant in the solid state. This anomalous behavior may originate from the strong hydrogen bonding between SMO and PCM molecules in the voids; the erythritol molecules may possess extensive hydrogen bonding, which is manifest in the enhanced specific heat.

Average supercooling degree and the difference in specific heats of bulk erythritol in solid and liquid state are larger $\left(94{ }^{\circ} \mathrm{C}\right.$ and 1.12 $\mathrm{J} / \mathrm{gK})$ as compared to the values of HIPE-ery $\left(65^{\circ} \mathrm{C}\right.$ and $\left.0.80 \mathrm{~J} / \mathrm{gK}\right)$, causing together the greater crystallization heat reduction of bulk erythritol. However, the crystallization heat reduction strongly depends on the crystallization temperature as presented in Fig. 5B. The measured crystallization heat follows the calculated one relatively well at a temperature range of $30-50{ }^{\circ} \mathrm{C}$, but decreases with smaller supercooling degrees. This behavior may originate from the slower speed of crystallization front due to higher viscosity of the supercooled liquid at lower temperatures, resulting in incomplete crystallization of the highly supercooled erythritol.

\section{Thermal properties of xylitol and xylitol-polystyrene composite}

Xylitol supercools easily and may retain the supercooled state for a long period of time. ${ }^{27}$ Neither the studied bulk xylitol nor the xylitolpolystyrene composite crystallized spontaneously only by cooling the sample at most to $-50{ }^{\circ} \mathrm{C}$ in the DSC experiments. Therefore, only the first melting peak of the PCM was observed in the measurements. Table 5 summarizes the thermal properties of the xylitol samples.

Melting properties of HIPE-xyl were similar than those of HIPE-ery. The melting temperature of HIPE-xyl was $\sim 15^{\circ} \mathrm{C}$ lower than that of bulk xylitol. In addition, xylitol-polystyrene composite melted at a wider temperature range than bulk xylitol as in the case of microstructured erythritol. The measured melting heat of HIPE-xyl was $100-125 \mathrm{~J} / \mathrm{g}$, being $~ 70 \%$ of the calculated one obtained from Equation (1) and corresponding well to the melting heat of HIPEery. The results of xylitol samples are only suggestive since the values present only the first melting cycle that may differ from subsequent phase change properties due to major changes occurring in the PCM microstructure during first melting cycle.
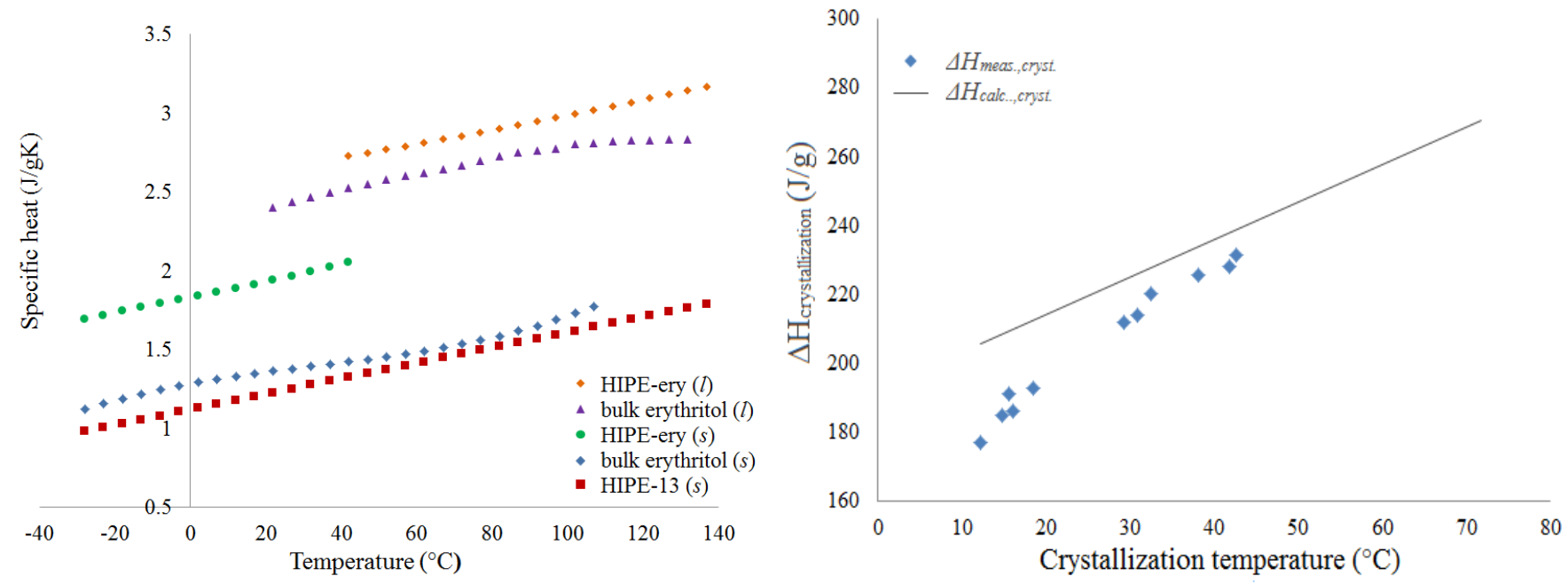

Fig. 6. A) Specific heats of bulk erythritol, HIPE-ery and HIPE-13 foam as a function of temperature. Phases of the samples (solid, $s$ or liquid, $l$ ) are presented in the legends. Specific heat of HIPE-ery is presented per total mass of the sample. B) Comparison of measured and calculated crystallization heats of bulk erythritol as a function of crystallization temperature 
Table 5. Melting properties of bulk xylitol and xylitol-polystyrene composite. Abbreviations: $T_{m}$. - extrapolated onset melting temperature, $\Delta H_{m}$. - average melting heat, $\Delta H_{\text {meas. }} / \Delta H_{\text {calc. }}-$ measured / calculated $\Delta H_{m}$. of HIPE-xyl (cf. Eq. (1)). Latent heats are reported per total mass of the samples.

\begin{tabular}{cccc}
\hline Sample & $\begin{array}{c}T_{m .} \\
\left({ }^{\circ} \mathrm{C}\right)\end{array}$ & $\begin{array}{c}\Delta H_{m .} \\
(\mathrm{J} / \mathrm{g})\end{array}$ & $\Delta H_{\text {meas }} . \Delta H_{\text {calc. }}$ \\
\hline Bulk xylitol & & & \\
$0.5 \mathrm{~K} / \mathrm{min}$ & $93 \pm 1$ & $236 \pm 4$ & - \\
$5 \mathrm{~K} / \mathrm{min}$ & $93 \pm 1$ & $241 \pm 2$ & - \\
HIPE-xyl & & & \\
$0.5 \mathrm{~K} / \mathrm{min}$ & $80 \pm 5$ & $110 \pm 10$ & 0.70 \\
$5 \mathrm{~K} / \mathrm{min}$ & $81 \pm 5$ & $115 \pm 10$ & 0.71 \\
\hline
\end{tabular}

The specific heats of bulk xylitol, xylitol-polystyrene composite and HIPE-13 foam as a function of temperature are shown in Fig. 6.

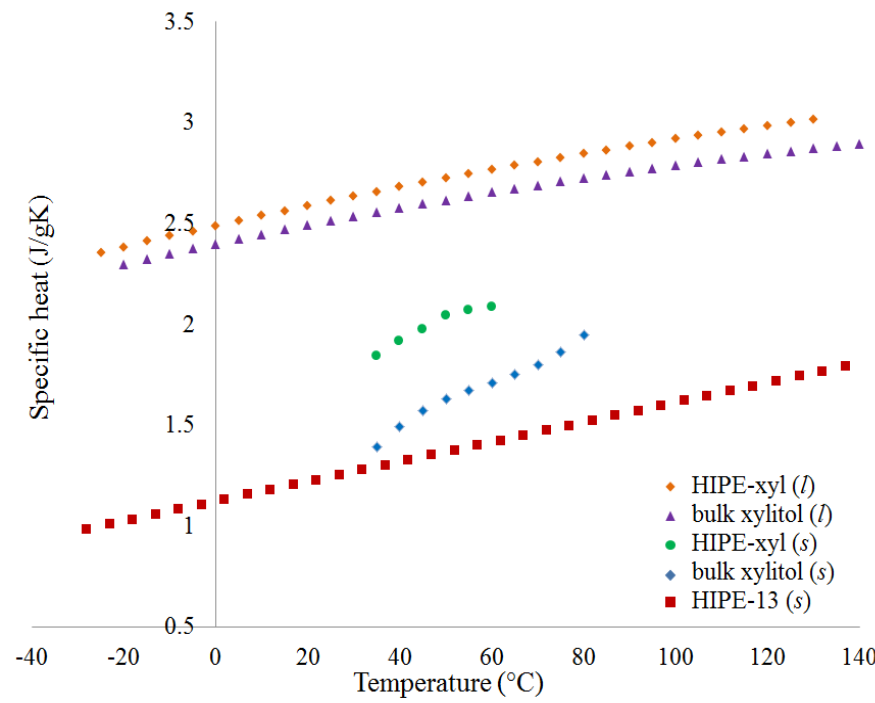

Fig. 6. Specific heats of bulk xylitol, HIPE-xyl and HIPE-13 foam as a function of temperature. Phases of the samples (solid, $s$ or liquid, $l$ ) are presented in the legends. Specific heat of HIPE-xyl is presented per total mass of the sample.

The specific heats of bulk xylitol and HIPE-xyl demonstrated similar behavior than in the case of erythritol samples; in both cases polyol-polystyrene composites showed enhanced specific heat as compared to the specific heats of bulk PCMs and HIPE foam. The specific heat increase is more profound in the solid state; $c_{p, H I P E}$ ${ }_{\text {xyl }} / \mathrm{c}_{\mathrm{p} \text {,bulk }}=1.31$ (solid state, $40^{\circ} \mathrm{C}$ ) and $\mathrm{c}_{\mathrm{p}, \mathrm{HIPE} \text {-xyl }} / \mathrm{c}_{\mathrm{p} \text {,bulk }}=1.04$ (liquid state, $\left.40^{\circ} \mathrm{C}\right)$.

\section{Conclusions}

We have demonstrated a novel, robust route to prepare microstructured PCMs based on the polymerization of high internal phase emulsions. Two supercooling polyols, xylitol and erythritol, were chosen as model PCMs for this study. Preparation parameters were optimized in order to obtain closed-cell foam structure with as small pore size and narrow pore size distribution as possible. The surfactant fraction had strongest influence on the formation of the foam structure and the crosslinker agent significantly enhanced the foam stability. The optimal ratios of SMO and DVB to the organic phase were found to be 5 and $30 \mathrm{wt}-\%$, respectively. The aqueous phase fraction was retained relatively low at $70 \mathrm{wt}-\%$, as stable and closed-cell polymeric foam was desired for development of microstructured PCMs.

Polyol-polystyrene composites were obtained by dissolving polyols into water after which the emulsion was formed, styrene-DVB matrix polymerized, and water vaporized.The maximum erythritol and xylitol fractions that could be engaged into the foam structure were $62 \mathrm{wt}-\%$ and $67 \mathrm{wt}-\%$ of the dry product weight, respectively. The void sizes of the polyol-polystyrene composites were $50 \mu \mathrm{m} \pm 40 \mu \mathrm{m}$.

Thermal properties of the novel microscale polyols were studied thoroughly by DSC and compared to the properties of bulk polyols. Microscale engineering was found have a strong influence on the thermal properties of the polyols studied here. The supercooling degree, melting heat, and melting temperature of microstructured erythritol were lower than those of bulk erythritol. Similar melting properties were observed for the microscale xylitol sample. The highly supercooled xylitol samples maintained as liquids in the studied conditions $\left(\mathrm{T} \geq-50 \quad{ }^{\circ} \mathrm{C}\right)$ and thus, the crystallization properties of xylitol samples could not be studied.

The crystallization of microstructured and bulk erythritol differed greatly from each other. The erythritol-polystyrene composite crystallized in more controlled manner than the bulk erythritol; the crystallization heats and temperatures of microscale erythritol varied substantially less.

In addition to phase change characteristics, the specific heats of the polyol samples were studied with DSC. Peculiarly, the specific heats of both microscale erythritol and xylitol samples were higher than those of bulk PCMs $\left(\mathrm{c}_{\mathrm{p}, \mathrm{HIPE}-\text { ery }} / \mathrm{c}_{\mathrm{p} \text {,bulk }}=1.42\right.$ and $\mathrm{c}_{\mathrm{p}, \mathrm{HIPE}-\mathrm{xyl}} / \mathrm{c}_{\mathrm{p}, \text { bulk }}=$ 1.31 at $40{ }^{\circ} \mathrm{C}$, solid state) despite the lower specific heat of the polystyrene foam. It is likely that strong SMO-polyol interactions give rise to enhanced hydrogen bonding in the microstructured polyol systems, resulting in larger specific heat of the HIPE samples.

Due to the substantial differences between the solid and liquid state specific heats and large supercooling degree of both erythritol samples, the crystallization heats of the samples were reduced as compared to the melting heats. For thermal energy storage, this reduction is clearly an undesired feature, and thus PCMs with smaller difference in $c_{p} s$ should be discovered. In addition, the heat storing potential of microstructured PCMs should be increased for TES. Higher heat storing potential of the composites could possibly be reached if the density and solubility inflicted problems in the emulsions preparation could be solved, in which case higher fraction of PCM could be engaged into the foam.

However, the polyol-polystyrene-composites proposed here are extremely interesting for further studies of heat storage purposes due to their more effective solidification and more reproducible phase change characteristics as compared to bulk polyols. In addition, high specific heats of the composites combined with the heat storing and insulative properties of polyols and polystyrene matrix, respectively, 
could make the proposed PCM-polystyrene composites attractive for heat or cold protection applications.

\section{Acknowledgements}

This work was carried out in the Efficient Energy Use (EFEU) research program coordinated by CLEEN Ltd. with funding from the Finnish Funding Agency for Technology and Innovation, Tekes, Fortum Foundation, Aalto Energy Efficiency Research Programme (EXPECTS-project) and supported in part by the Academy of Finland through its COMP CoE grant \#251748.

\section{Notes and references} a Aalto University School of Engineering, Department of Energy
Technology, P.O. Box 14400, FIN-00076 Aalto, Espoo, Finland
b Aalto University School of Science, Department of Applied
Physics and COMP CoE, P.O. Box 11000, FIN-00076 Aalto,
Espoo, Finland
${ }^{c}$ Brown University, Department of Physics, P.O. Box 1843, Providence, RI
02912, USA
$\dagger \quad$ Corresponding author: Salla Puupponen: e-mail
salla.puupponen@aalto.fi / tel. +358407277756

1 M. M. Farid, A. M. Khudhair, S. A. K. Razack, S. AlHallaj, Energ. Convers. Manage., 2004, 49, 1597-1615.

2 A. Sharma, V. V. Tyagi, C. R. Chen, D. Buddhi, Renewable Sustainable Energ. Rev., 2009, 13, 318-345.

3 B. Zalba, J. M. Marín, L. F. Cabeza, H. Mehling, Appl. Therm. Eng., 2003, 23, 251-283.

4 A. Seppälä. Int. J. Heat Mass Tran., 2012, 55, 1582-1595.

5 A. Sagara, T. Nomura, M. Tsubota, N. Okinaka, T. Akiyama, Mater. Chem. Phys., 2014, 146, 253-260.

6 F. Salaün, E. Devaux, S. Bourbigot, P. Rumeau,. Carbohydr. Polym., 2008, 73, 231-240.

7 F. Salaün, G. Bedek, E. Devaux, D. Dupont, L. Gengembre, J. Membr. Sci., 2011, 370, 23-33.

8 D. Barby Z. Haq, U.S. Patent, 4,522,953 (Unilever applicant) Juny 11, 1985.

9 J. M. Williams, D. A. Wrobleski, Langmuir, 1988, 4, 656662.

10 J. M. Williams, A. J. Gray, M. H. Wilkerson,. Langmuir, 1990, 6, 437-444.

11 A. Seppälä, M. El Aj Hassad, T. Kapanen, Struct. Multidisc. Optim., 2008, 36, 355-363.

12 J. J. Zhang, Z. G. Qu, Z. G. Jin, Energy, 2014, 71, 94-103.

13 D. P. Putnam, M. Nair, M. C. Brick, T. K. Jones, U.S. Patent, 8,252,414, August 28, 2012.

14 M. Nair, C. P. Lusignan, D. C. Boris, Colloids Surf., A, 2014, 443, 583-595.

15 Y. He, Y. Cao, Y. Liu, J. Polym. Sci., Part B: Polym. Phys., 2005, 43, 2617-2624.

16 M. Bradely, F. Grieser, J. Colloid Interface Sci., 2002, 251, 78-84.

17 Y. Kojima, S. Koda, H. Nomura, Ultrason. Sonochem., $2001,8,75-79$. 29, 295-326.

20 A. S. Ostroski, R. B. Stambaugh, J. Appl. Phys., 1950, 21(478), 478-482.

21 G. Madras, S. Kumar, S. Chattopadhyay, Polym. Degrad. Stab., 2000, 69, 73-78.

22 H. W. Melville, A. J. R. Murray, Trans. Faraday Soc., 1950, 46, 996-1009.

23 J. S. Redinha, A. J. L. Jesus A. A. C. C. Pais, J. A. S. Almeida, in Advanced Topics of Crystal Growth, Intech, 2013, Ch. 8, pp. 201-224.

24 A. J. L. Jesus, S. C. C. Nunes, M. R. Silva, A. M. Beja, J. S. Redinha Int. J. Pharm., 2010, 388, 129-135.

25 R. A. Talja, Y. H. Roos, Thermochim. Acta, 2001, 380, 109-121.

26 L. Carpentier, S. Desprez, M. Descamps, J. Therm. Anal. Calorim. 2003, 73, 577-586.

27 A. Seppälä, A. Meriläinen, L. Wikstrom, P. Kauranen, Exp. Therm. Fluid Sci., 2010, 34(5), 523-527.

28 A. J. L. Jesus, L. I. N. Tomé, J. S. Redinha, M. E. Eusébio, J. Phys. Chem. B, 2005, 109, 18055-18060.

29 G. Barone, G. D. Gatta, D. Ferro, V. Placente, J. Chem. Soc., Faraday Trans., 1990, 86(1), 75-79.

30 Q. Jing, M. D. Ward, Chem. Soc. Rev., 2014, 43, 20662079.

31 S. Puupponen, A. Seppälä, O. Vartia, K. Saari, T. AlaNissilä, Thermochim. Acta, 2015, 601, 33-38. 